\title{
Diagnóstico laboratorial da infecção pelo vírus herpes simples (HSV) em pacientes transplantados e não-transplantados
}

\author{
Laboratorial diagnosis of herpes simplex virus infection (HSV) in transplanted and non-transplanted patients
}

Rafael B. Varella; Ivone L. Pires; Carlos Alberto Saraiva; Antônio Carlos C. Guimarães; Maria Angélica A. M. Guimarães

unitermos Virus herpes simples

Cultura de célula

PCR

Transplante

\section{resumo}

Introdução: O vírus herpes simples (HSV) é dividido em dois sorotipos (HSV-1 e HSV-2) responsáveis, respectivamente, pelos herpes labial e genital. Embora a infecção pelo HSV tenha um curso rápido, esse agente está freqüentemente relacionado a complicações no tratamento de pacientes imunocomprometidos, como indivíduos transplantados, na condição de agente oportunista. Objetivos: Comparar e avaliar o uso de três técnicas atuais para diagnóstico de HSV em pacientes transplantados e nãotransplantados. Material e métodos: Oitenta e quatro amostras clínicas consecutivas provenientes de 47 indivíduos transplantados e 37 não-transplantados foram coletadas de junho de 2001 a julho de 2002, sendo, simultaneamente, submetidas a nested multiplex reação em cadeia da polimerase (PCR) (nmPCR), multiplex PCR (mPCR) e isolamento viral (IV) em células vero. Resultados: Das amostras, 33,3\% (28/84) foram positivas para o HSV por IV, 34,5\%(29/84) por mPCR e 42,8\% (36/84) por nmPCR. Pela técnica de imunofluorescência direta (IFD), 85,7\% (24/28) das amostras foram caracterizadas como HSV-1, 86,2\% (25/29) pelo mPCR e 88,9\%(32/36) pelo nmPCR. Foram caracterizadas como HSV-2 pelas três técnicas empregadas $4,8 \%(4 / 84)$ das amostras. Não houve diferença significante de detecção entre as técnicas de diagnóstico do $\operatorname{HSV}(p=0,38)$, embora o nmPCR tenha detectado mais amostras de pacientes transplantados $(p=0,05)$. Conclusão: Apesar do desempenho similar entre as técnicas, o nmPCR se mostrou ferramenta útil para pacientes transplantados ou para aqueles sob tratamento antiviral, onde é esperada baixa carga viral em suas amostras.

Background: Herpes simplex virus (HSV) is divided in two serotypes (HSV-1 and HSV-2) responsible for labial end genital herpes, respectively. Although the infection caused by HSV has a rapid course, this agent is frequently related to complications in immunocompromised patient's treatment, like transplanted individuals as an opportunistic agent. Objectives: To compare and evaluate three current diagnosis techniques for HSV diagnosis in transplanted and non-transplanted patients. Material and methods: 84 consecutive clinical samples from 47 transplanted and 37 non-transplanted individuals were collected from June 2001 to July 2002, being simultaneously submitted to nested multiplex $P C R(n m P C R)$, multiplex $P C R(m P C R)$ and viral isolation $(V I)$ in Vero cells. Results: $33.3 \%(28 / 84)$ samples were HSV-positive by VI, 35.4\%(29/84) by mPCR and $42.8 \%(36 / 84)$ by nmPCR. 85.7\% (24/28) samples were characterized as HSV-1 by the direct immunofluorescence technique (dIF), $86.2 \%(25 / 29)$ by mPCR and $88.9 \%(32 / 36)$ by nmPCR. 4.8\%(4/84) samples were characterized as HSV-2 by the three techniques. There was no significant difference regarding HSV diagnosis among the techniques ( $p=$ $0.38)$, although $n m P C R$ detected more samples from transplanted patients $(p=0.05)$. Conclusion: although the three techniques presented similar performances, the nmPCR revealed to be an useful tool for transplanted patients or those under antiviral treatment, where a low viral load in their samples is expected.

Laboratório de Virologia, Departamento de Patologia Clínica do Hospital Universitário Clementino Fraga Filho da Universidade Federal do Rio de Janeiro (HUCFF/UFRI).

\section{key words} Herpes simplex virus $P C R$ Cell culture Transplant 


\section{Introdução}

O vírus herpes simples (HSV) é membro da extensa e heterogênea família Herpesviridae, composta por inúmeros patógenos animais e humanos, como citomegalovírus (CMV), Epstein-Barr (EBV) e varicela-zoster (VVZ). O HSV é dividido em dois sorotipos, HSV-1 e HSV-2, responsáveis pelos herpes labial e genital, respectivamente ${ }^{(1)}$. $O$ vírus tem como característica biológica o rápido crescimento em cultivo celular, uma ampla gama de hospedeiros e a capacidade, comum a todos os herpesvírus, de se manter latente em células de seus hospedeiros por tempo indeterminado(2).

O herpes é uma das infecções humanas mais comuns(2,3), embora manifestações mais severas possam ocorrer entre neonatos e indivíduos imunocomprometidos, incluindo HIV-positivos e transplantados ${ }^{(4)}$. De fato, nesses pacientes, as manifestações causadas pelo herpes podem variar de formações vesiculares limitadas às regiões orofacial e genital até doença disseminada em pele e mucosas, com freqüente acometimento do sistema nervoso central (SNC), deixando seqüelas em $80 \%$ de suas vítimas ${ }^{(5)}$. Além da gravidade e da cronicidade da doença, é comum o relato de isolamento de amostras resistentes ao aciclovir (ACV), a primeira droga de escolha para o tratamento contra o vírus nesse tipo de paciente ${ }^{(6)}$. Este fator complicador dificulta e redireciona o tratamento para drogas alternativas como valaciclovir, penciclovir e foscarnet, embora problemas de toxicidade e resistência viral já tenham sido detectados para estas drogas $^{(7-10)}$. Em relação ao diagnóstico laboratorial, 0 isolamento viral (IV), apesar de lento e trabalhoso, ainda é considerado o método padrão para diagnóstico do HSV, e se baseia na observação de uma cultura de células sob microscópio ótico à procura do efeito citopático (ECP) do vírus sobre a célula ${ }^{(11)}$. Entretanto novas técnicas moleculares, como a reação em cadeia da polimerase (PCR) e a captura híbrida, estão em desenvolvimento e vêm sendo capazes de detectar pequenas quantidades de genoma viral numa amostra de forma mais rápida (algumas horas, em contraste com os sete dias, em média, do isolamento) ${ }^{(11-}$ 13). Apesar de serem evidentes as vantagens das técnicas moleculares em relação ao isolamento do vírus em cultivo celular, sua aplicação de acordo com a população sob investigação (transplantados e não-transplantados) ainda não tinha sido avaliada.

Portanto, o objetivo deste trabalho foi comparar e avaliar o emprego de técnicas moleculares e isolamento viral para diagnóstico do HSV em amostras de pacientes transplantados e não-transplantados.

\section{Material e métodos}

\section{Coleta de amostras}

Oitenta e quatro amostras consecutivas com suspeita clínica de herpes (uma por indivíduo) foram coletadas de 47 transplantados (tx) e de 37 não-transplantados (não-tx) atendidos no Hospital Universitário Clementino Fraga Filho da Universidade Federal do Rio de Janeiro (HUCFF/UFRJ), de junho de 2001 a julho de 2002. Apenas os indivíduos tx estavam recebendo ACV intravenoso como profilaxia. As amostras foram coletadas de vesículas da pele e de mucosas oral, vaginal e perianal, com auxílio de swab umedecido. $\mathrm{O}$ material coletado foi levado ao nosso laboratório em meio de transporte ( $1 \mathrm{ml}$ de MEM [Eagle] com 100Ul de penicilina, $20 \mu \mathrm{g} / \mathrm{ml}$ de gentamicina e $2,5 \mu \mathrm{g} / \mathrm{ml}$ de fungizona) e mantido a $4^{\circ} \mathrm{C}$ antes do manuseio.

\section{Método de isolamento viral em cultura de células}

O isolamento viral foi realizado através da inoculação de $100 \mu$ do material vesicular coletado dos pacientes em cultura de células vero (em duplicatas), crescidas nos tubos $13 \times 100 \mathrm{em} 1 \mathrm{ml}$ de meio de cultura MEM (Eagle) com 2\% de soro fetal bovino (Gibco) e acrescida de antibióticos. A cultura de células foi observada diariamente à procura de ECP característico promovido pelo HSV (arredondamento e morte celular) por duas semanas. Na ausência de ECP, passagens cegas eram feitas no 15 - dia e o procedimento se repetia mais uma vez.

\section{Identificação do sorotipo do HSV por imunoflu- orescência direta}

A técnica de imunofluorescência direta (IFD) é utilizada para confirmação e sorotipagem do HSV proveniente de isolamento do vírus em cultura de células. Basicamente, células vero apresentando $80 \%$ de ECP foram vigorosamente agitadas para separação e centrifugadas ( 3 mil RPM/5min). Da suspensão celular, $200 \mu \mathrm{l}\left(10^{6}\right.$ células $/ 1 \mathrm{ml}$ de solução tampão salina de fosfato [PBS]) foram centrifugados em lâmina com auxílio de uma citocentrífuga. Após isso, as células aderidas à lâmina foram fixadas com acetona fria por $10 \mathrm{~min}$ em temperatura ambiente. Anticorpos monoclonais específicos (Pasteur) foram adicionados às células fixadas e incubados à temperatura ambiente por 45 min em câmara escura. Controles positivos e negativos foram utilizados em cada ensaio. Depois da incubação, as lâminas foram lavadas com PBS $(\mathrm{pH} 7,4)$ e observadas em microscópio de 
fluorescência (Zeiss) à procura de corpúsculos de inclusão, característicos do HSV.

\section{Diagnóstico e tipagem das amostras por PCR}

Para a realização das técnicas de PCR (multiplex PCR e nested multiplex PCR), uma extração prévia do DNA viral foi feita com proteinase K (Gibco BRL), de acordo com instruções do fabricante. Para o mPCR, foram empregados primers (Gibco BRL) específicos para ambos os sorotipos de HSV e para cada um deles, separadamente (Tabela 1). No caso do nmPCR, primers (Gibco BRL) para os genes US-4 e UL-42, específicos para HSV-2 e HSV-1, respectivamente, foram empregados (Tabela 1). O mPCR foi feito em um volume de $50 \mu \mathrm{l}$ contendo $2,5 \mu \mathrm{l}$ da amostra clínica, $1,5 \mathrm{mM}$ de $\mathrm{MgCl}, 50 \mathrm{mM}$ de $\mathrm{KCl}, 10 \mathrm{mM}$ de Tris/HCl, $200 \mu \mathrm{M}$ de dNTPmix, 0,2 $\mu \mathrm{M}$ de cada primer e 2,5U de taq-polymerase (Gibco-BRL). A amplificação foi realizada em 35 ciclos tal como segue: desnaturação a $94^{\circ} \mathrm{C}$ por $48 \mathrm{~s}$, anelamento a $55^{\circ} \mathrm{C}$ por $18 \mathrm{~s}$ e alongamento a $72^{\circ} \mathrm{C}$ por 48 s. A primeira fase do nmPCR foi feita em $25 \mu$ le solução contendo $5 \mu \mathrm{l}$ da amostra clínica, $1,5 \mathrm{mM}$ de $\mathrm{MgCl}, 50 \mathrm{mM}$ de $\mathrm{KCl}, 10 \mathrm{mM}$

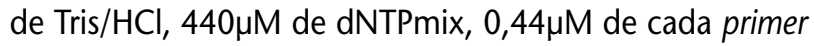
externo e 2,5U de taq-polymerase. A amplificação foi realizada como já descrito. Na segunda fase, $5 \mu l$ do material amplificado obtido no primeiro ciclo foram reamplificados sob as mesmas condições da primeira fase, utilizando-se $0,2 \mu \mathrm{M}$ de cada primer interno (Tabela 1). A amplificação foi feita em 15 ciclos: desnaturação a $94^{\circ} \mathrm{C}$ por 48 s, anelamento a $65^{\circ} \mathrm{C}$ por 18 s e alongamento a $72^{\circ} \mathrm{C}$ por $48 \mathrm{~s}$. Os amplicons foram adicionados ao gel de agarose (2\%) previamente corado com brometo de etídio para eletroforese por duas horas. Após esse período o gel foi visualizado em leitor de ultravioleta.

\section{Avaliação da capacidade de deteç̧ão das técni- cas de diagnóstico empregadas}

Com o objetivo de comparar os dois métodos de PCR utilizados neste estudo com o isolamento viral, desenvolvemos um teste semelhante ao empregado por Diaz-Mitoma et al. (14). Amostras-padrão de HSV-1 e HSV-2 foram diluídas (1:10) e 50ul de cada diluição (amostra bruta até a diluição de $10^{-8}$ ) foram inoculados em tubos contendo células vero. Após 48h, a cultura celular foi observada na procura de efeito citopático induzido pelo HSV. O sobrenadante de cada tubo foi coletado e submetido aos PCRs como descrito anteriormente.

\section{Resultados}

\section{Isolamento do HSV em cultura celular e soroti- pagem por imunofluorescência direta}

Das 84 amostras inoculadas em cultura de células vero, 24 (33,3\%) apresentaram efeito citopático sugestivo de HSV (Tabela 2). O isolamento viral detectou 25/37 $(67,6 \%)$ e $3 / 47$ (6,4\%) amostras de pacientes tx e não-tx, respectivamente (Tabela 2). A técnica de IFD revelou que $24 / 28(85,7 \%)$ e $4 / 28(14,3 \%)$ das amostras pertenciam aos subtipos HSV-1 e HSV-2, respectivamente (Tabela 3, Figura 1). Das $4 / 28(14,3 \%)$ amostras caracterizadas como sorotipo 2, 2/4 (50\%) foram coletadas da área genital,

\section{Tabela 1}

\section{Sequiência de primers utilizados para MPCR e nmPCR}

\begin{tabular}{lllll}
\hline Técnica & Primer & Seqüência $\left(5^{\prime}-3^{\prime}\right)$ & Gene alvo & Produto \\
mPCR & HSV1 P3-1 & CCTCGCGTTCGTCCTGGTCCTCC & DNApol & 469pb \\
& HSV1e 2 P5 & ATGGTGAACATCGACATGTACGG & DNA-pol & - \\
& HSV2 P3-2 & CCTCCTTGTCGAGGCCCCGAAAC & DNA-pol & 391pb \\
nmPCR & HSV1-D2 primer externo & GCT TTG TGG TGG TT & UL-42 & \\
& HSV1-R2 primer externo reverso & CTG GTG GTG GAC CAC AC & UL-42 & \\
& HSV1-D3 primer interno & CCC CGA CGT TCA GTT GCG CCT GAC G & UL-42 & \\
& HSV1-R3 primer reverso interno & TCC TCG CGG GCA GCA AAG GTG ACG C & UL-42 & 159pb \\
& HSV2-D1 primer externo & ACG TAC TAC CGG CTC AC & US-4 & \\
& HSV2-R1 primer externo reverso & CCA CCT CTA CCC ACA AC & US-4 & \\
& HSV2-D3 primer interno & CCG CGC CTG CCG TCA GCC CAT CCT C & US-4 & \\
HSV2-R3 primer reverso interno & AGA CCC ACG TGC AGC TCG CCG & US-4 & 225pb \\
\hline
\end{tabular}


enquanto as outras duas da região orolabial. Das 24/28 $(85,7 \%)$ amostras caracterizadas como sorotipo 1, 20/24 $(83,3 \%)$ foram coletadas da região orolabial, $3 / 24$ (12,5\%) da região perianal e $1 / 24(4,2 \%)$ do dedo (Tabela 3).

\section{Deteç̧ão e tipagem das amostras por multiplex PCR e nested multiplex PCR}

Das 84 amostras, 29 (34,5\%) foram positivas por $\mathrm{MPCR}$, enquanto 36 (42,8\%), por nmPCR (Tabela 2, Figuras 2 e 3). O mPCR detectou $25 / 37(67,6 \%)$ e $4 / 47(8 ., 5 \%)$ amostras de pacientes não-tx e tx, respectivamente, enquanto o nmPCR, 26/37 (70,3\%) e 10/47 (21,3\%) amostras de pacientes não-tx e $\mathrm{tx}$, respectivamente (Tabela 2). $\mathrm{O}$ nmPCR caracterizou 32/36 (88,8\%) amostras de HSV-1 e $4 / 36(11,1 \%)$ como HSV-2, enquanto o mPCR detectou as mesmas $4 / 29(13,8 \%)$ amostras de HSV-2 e 25/29 (86,2\%) de HSV-1 (Tabela 3). Nenhuma discrepância em relação à tipagem das amostras ocorreu entre as técnicas moleculares e o isolamento viral (Tabela 3).

\section{Avaliação da capacidade de detecção das técni- cas empregadas}

A comparação entre o isolamento viral e as técnicas de PCR (mPCR e nmPCR) revelou que o efeito citopático em cultura de células foi observado até a diluição de $10^{-1}$,

\begin{tabular}{|c|c|c|c|}
\hline Tabela 2 & \multicolumn{3}{|c|}{$\begin{array}{l}\text { Comparação entre as diferentes } \\
\text { técnicas de diagnóstico }\end{array}$} \\
\hline Técnica & $\begin{array}{l}\text { Positivos }^{1} \\
\quad \%\end{array}$ & $\begin{array}{l}\text { Positivos }^{2} \\
\%\end{array}$ & $\begin{array}{l}\text { Total } \\
\%\end{array}$ \\
\hline IV & $67,6(25 / 37)$ & $6,4(3 / 47)$ & $33,33(28 / 84)$ \\
\hline mPCR & $67,6(25 / 37)$ & $8,5(4 / 47)$ & $34,5(29 / 84)$ \\
\hline nmPCR & $70,3(26 / 37)$ & $21,3(10 / 47)$ & $42,9(36 / 84)$ \\
\hline$p$ & 0,95 & 0,05 & 0,38 \\
\hline
\end{tabular}

1: pacientes não-transplantados; 2: pacientes transplantados

enquanto o genoma viral foi detectado visualmente até as diluições de $10^{-3}$ e $10^{-5}$ para o $\mathrm{mPCR}$ e o $\mathrm{nmPCR}$, respectivamente. $\mathrm{O}$ resultado, portanto, revelou que o $\mathrm{nmPCR}$ foi capaz de detectar o HSV em uma quantidade $10^{2}$ e $10^{4}$ menores do que as técnicas de mPCR e isolamento viral, respectivamente.

\section{Discussão}

As manifestações clínicas causadas pelo vírus herpes simples variam do herpes labial comum até encefalites fatais e necrose de órgãos. Essa enorme variabilidade de

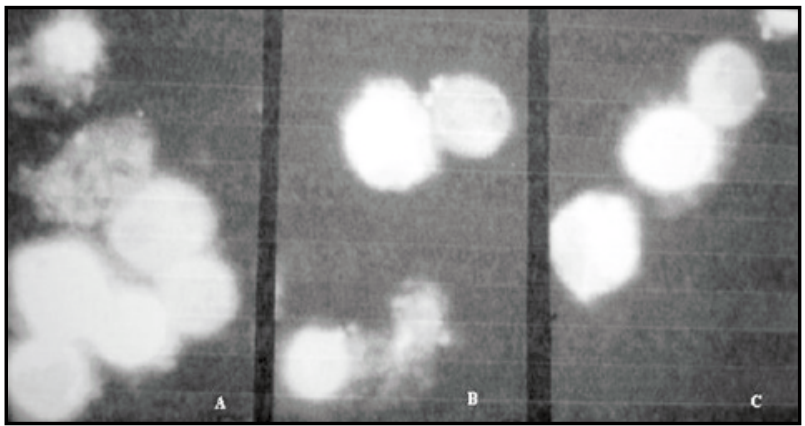

Figura 1

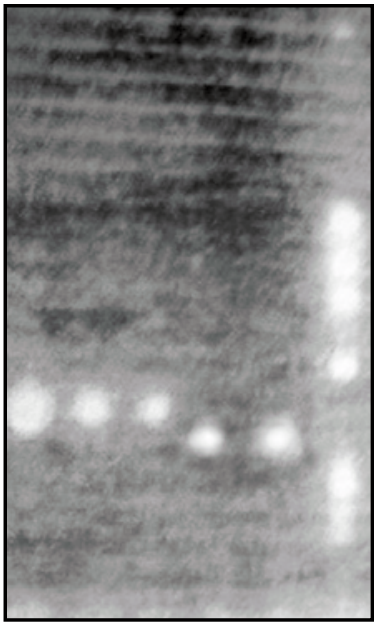

Figura 2

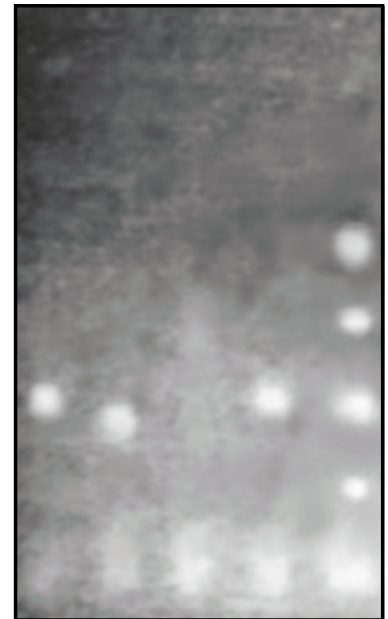

Figura 3

\begin{tabular}{|c|c|c|c|c|c|c|c|}
\hline Local & Vesícula oral & Mucosite oral & Úlcera & $\begin{array}{c}\text { Vesícula } \\
\text { genital }\end{array}$ & $\begin{array}{l}\text { Vesícula } \\
\text { perianal }\end{array}$ & $\begin{array}{l}\text { Vesícula } \\
\text { de pele }\end{array}$ & Total \\
\hline \multicolumn{8}{|c|}{ Técnica } \\
\hline IV & $19^{1}(2)^{2}$ & $1(0)$ & - & $0(2)$ & $3(0)$ & $1(0)$ & $24(4)$ \\
\hline $\mathrm{mPCR}$ & $20(2)$ & $1(0)$ & - & $0(2)$ & $3(0)$ & $1(0)$ & $25(4)$ \\
\hline nmPCR & $22(2)$ & $3(0)$ & $2(0)$ & $0(2)$ & $3(0)$ & $1(0)$ & $32(4)$ \\
\hline
\end{tabular}

1: HSV-1; 2: HSV-2. 
sintomas clínicos depende da virulência e da resistência da cepa viral à medicação, além do status imunológico do paciente ${ }^{(15)}$.

O diagnóstico laboratorial para o HSV tem aplicação complementar para as manifestações comuns causadas pelo vírus (vesículas orolabiais e genitais), embora seja importante para indivíduos imunocomprometidos, transplantados, gestantes, recém-natos e em suspeita de encefalite. Em todos os casos e, principalmente, para os de maior gravidade, é necessário o desenvolvimento de técnicas diagnósticas mais rápidas e sensíveis que possam detectar o vírus em tecidos diferentes e em pequenas quantidades ${ }^{(16,17)}$.

O isolamento viral, padrão-ouro para o diagnóstico de herpes, apesar de sua boa sensibilidade ${ }^{(18,19)}$, tem sido substituído por técnicas moleculares como a PCR ${ }^{(20-22)}$. Tais técnicas são de rápida execução e mais sensiveis do que as convencionais.

A técnica de nmPCR empregada neste estudo foi capaz de detectar um número significativamente maior de amostras provenientes de pacientes tx $(p=0,05)$, embora não tenham sido observadas diferenças significantes quando comparamos essa técnica com o mPCR e o isolamento viral para amostras de pacientes não-tx $(p=0,95)$ (Tabela 2). Esse aparente desacordo pode ser explicado pelo fato de os pacientes tx sob contínuo tratamento profilático com o ACV apresentarem amostras com baixa carga viral, permitindo que uma técnica mais sensível, como o nmPCR, possa detectar o vírus. $O$ desempenho superior do nmPCR já era esperado, pois se trata de uma técnica que se diferencia das demais pela característica metodológica de realizar PCR sobre um amplicom (nested), aumentando ainda mais as chances de detecção. Já os pacientes não-tx (sem tratamento antiviral profilático) apresentariam amostras com carga viral mais elevada, permitindo que técnicas com menor sensibilidade, como o MPCR e o isolamento viral, detectassem o HSV mesmo quando um desempenho superior do mPCR fosse esperado (34,5\% vs. $33,3 \%$ do isolamento viral). Esse fato também explica o baixo índice de positivos entre os transplantados de uma forma geral.

Além dos pacientes $t x$, algumas amostras exclusivamente diagnosticadas por nmPCR eram provenientes de mucosites e úlceras, que possuem carga viral notadamente mais reduzida. Tal capacidade de detecção foi confirmada quando observamos uma superioridade de 2 e $4 \log$ do nmPCR em relação ao mPCR e o isolamento viral, respectivamente.

Em relação à presença de sintomas, observamos que $62,5 \%$ dos indivíduos tx apresentavam manifestações semelhantes às do herpes, notadamente mucosite, sem a presença do HSV, em contraste com apenas $16,6 \%$ dos pacientes não-tx $(p<0,002)$ (dado não-apresentado). A medicação antiviral, somada a drogas imunossupressoras e agentes oportunistas, pode ter causado essa alta prevalência de manifestações herpes-like ${ }^{(14)}$, que devem ser consideradas previamente à medicação.

\section{Conclusão}

Os resultados aqui obtidos indicam que a técnica de nmPCR, apesar de apresentar taxas de detecção semeIhantes ao PCR e ao isolamento viral para pacientes nãotx, mostrou-se uma ferramenta extremamente útil para o diagnóstico de herpes, especialmente para situações em que os métodos convencionais são falhos, como para pacientes transplantados e em suspeita de encefalite herpética, em que um resultado rápido e sensível é vital(23).

\section{Referências}

I. BOIVIN, G. Diagnosis of herpesvirus infections of the central nervous system. Herpes, v. 2, suppl., p. 48-56, 2004.

2. COLLINS, P.; ELLIS, N. Sensitivity monitoring of clinical isolates of herpes simplex virus to acyclovir. J Med Virol, v. I, suppl., p. 58-66, 1999.

3. COYLE, P. V. et al. A comparison of virus isolation, indirect immunofluorescense and nested polymerase chain reaction for the diagnosis of primary and recurrent herpes simplex I and type 2 infections. J Virol Meth, v. 83, p. 75-82, 1999.

4. CULLEN,A. P.; LONG, C. D.; LÖRINCZ,A.T. Rapid detection and typing of herpes simplex virus DNA in clinical specimens by the hybrid capture II signal amplification probe test.J Clin
Microbiol,v. 35, n. 9, p. 2275-8, 1997.

5. DAN, K. et al. Quantitation of herpes simplex viral DNA in Vero cells for evalution of na antiviral agent using the polymerase chain reaction. J Virol Meth, v. 76, p. 73-9, 1998.

6. DIAZ-MITOMA, F. et al. Detection of viral DNA to evalute outcome of antiviral treatment of patients with recurrent genital herpes. J Clin Microbiol, v. 34, n. 3, p. 657-63, 1996.

7. ERLICH, K. S. et al. Acyclovir-resitant herpes simplex virus infections in patients with acquired immunodeficiency syndrome. N Engl J Med, v. 320, p. 293-6, 1989.

8. GERSHENGORN, H. B. B. S.; BLOWER, S. M. Impact of antivirals and emergence of drug resistance: HSV-2 epidemic control. 
Aids Patient Care STDS, v. 14, n. 3, p. 133-42, 2000.

9. HILL, E. L.; HUNTER, G.; ELLIS, M. N. In vitro and in vivo characterization of herpes simplex virus clinical isolates recovered from patients with immunodeficiency virus. Antimicrob Agents Chemother, v. 35, p. 2322-8, 1991.

10. HIRSCH, M. S.; KAPLAN, J. C.; D’ÁQUILA, R.T. Antiviral agents. In: FIELDS, B. N.; KNIPE, D. M.; ROWLEY, P. Virology. 3. ed. Philadelphia: Raven Publishers, 1996. cap 3, p. 43I-67.

I I. KIMBERLIN, D. Herpes simplex virus, meningitis and encephalitis in neonates. Herpes, v. 2, suppl., p. 65-76, 2004.

12. MILLER, C. S. et al. The efficacy of valacyclovir in preventing recurrent herpes simplex virus infections associated with dental procedures. J Am Dent Assoc, v. 135, n. 9, p. 1311-8, 2004.

13. MIRANDA, M. M. F. S. et al.Viroses dermotrópicas. In: SANTOS, N. S. O. S.; ROMANOS, M. T. V.; WIGG, M. D. Introdução à virologia humana. I. ed. Rio de Janeiro: Guanabara Koogan, 2002. cap. 7, p. 75-85.

14. MORFIN, F; THOUVENOT, D. Herpes simplex resistance to antiviral drugs. J Clin Virol, v. 26, p. 29-37, 2003.

15. NAHMIAS, A. J.; LEE, F. K.; BECKMAN-NAHMIAS, S. Seroepidemiological and sociological Patterns of Herpes Simplex Virus Infection in the World. Scand J Infect Dis Suppl, v. 69, p. 19-36, 1999

16. NASCIMENTO, M. C. et al. Detection and direct typing of herpes simplex virus in perianal ulcers of patients with AIDS by PCR. J Clin Microbiol, v. 36, n. 3, p. 848-9, 1998.

17. ROIZMAN, B.; SEARS, A. Herpes simplex virus and their replication. In: FIELDS, B. N.; KNIPE, D. M.; ROWLEY, P. Virology. 3. ed. Philadelphia: Raven Publishers, 1996. cap 8, p. 223I-95.

18. SAFRIN, S.; ELBEIK, T.; MILLS, J. A rapid screen for in vitro susceptibility of clinical herpes simplex virus isolates. I Infect Dis, v. 169, p. 879-82, 1993.

19. SARISKY, R. T. et al. Difference in incidence of spontaneous mutations between herpes simplex virus type 1 and 2 . Antimicrob Agents Chemother, v. 44, n. 6, p. 1524-9, 2000.

20. SCOTT, D. A. et al. Detection of herpes simplex virus type । shedding in the oral cavity by polymerase chain reaction and enzyme linked immunosorbent assay at the prodomal stage of recrudescent herpes labialis. J Oral Pathol Med, v. 23, p. 305-9, 1997.

2I.SKINNER, G. R. B. et al.A system for isolation, transport and storage of herpes simplex viruses.J Virol Meth, v. 65, p. I-8, 1997.

22. SLOMKA, M. J. et al. A comparison of $P C R$ with virus isolation and direct typing of genital herpes. J Med Virol, v. 55, p. 177 83, 1998.

23.WHITLEY, R. J. Herpes simplex viruses. In: FIELDS, B. N.; KNIPE, D. M.; ROWLEY, P. Virology. 3. ed. Philadelphia: Raven Publishers, 1996. cap I I, p. 2297-342. 